\title{
Robots, standards and the law: Rivalries between private standards and public policymaking for robot governance
}

\author{
Eduard Fosch Villaronga ${ }^{a, *}$, Angelo Jr Golia ${ }^{b}$ \\ ${ }^{a}$ Microsoft Cloud Computing Research Center \& Center for Commercial Law Studies (CCLS) at Queen Mary \\ University of London, 67 - 69 Lincoln's Inn Fields London WC2A 3JB, United Kingdom \\ ${ }^{\mathrm{b}}$ School of Political Sciences, University of Salerno, Italy
}

\section{A R T I C L E I N F O}

\section{Article history:}

Available online $\mathrm{xxx}$

Keywords:

Standard

Standardization

Lawmaking

Robots

Artificial intelligence

Policy

Human-robot interaction

Private actors

Public regulatory bodies

\begin{abstract}
A B S T R A C T
This article explains the complex intertwinement between public and private regulators in the case of robot technology. Public policymaking ensures broad multi-stakeholder protected scope, but its abstractness often fails in intelligibility and applicability. Private standards, on the contrary, are more concrete and applicable, but most of the times they are voluntary and reflect industry interests. The 'better regulation' approach of the EU may increase the use of evidence to inform policy and lawmaking, and the involvement of different stakeholders. Current hard-lawmaking instruments do not appear to take advantage of the knowledge produced by standard-based regulations, virtually wasting their potential benefits. This fact affects the legal certainty with regards to a fast-paced changing environment like robotics. In this paper, we investigate the challenges of overlapping public/private regulatory initiatives that govern robot technologies in general, and in the concrete of healthcare robot technologies. We wonder until what extent robotics should be governed only by standards. We also reflect on how public policymaking could increase their technical understanding of robot technology to devise an applicable and comprehensive framework for this technology. In this respect, we propose different ways to integrate the technical know-how into policymaking (e.g., collecting the data/knowledge generated from the im-
\end{abstract}

\footnotetext{
* This paper is the result of a joint effort of the two authors. However, Section III and the Proposal 1 in Section IV are more properly attributable to Eduard Fosch-Villaronga, while Section II and the Proposals 2 and 3 in Section IV are more properly attributable to Angelo Jr Golia. All the other parts are attributable to both authors.

This paper has been produced by a member of the Microsoft Cloud Computing Research Centre, a collaboration between the Cloud Legal Project at the Centre for Commercial Law Studies University of London and the Computer Laboratory, University of Cambridge. The author is grateful to Microsoft for the generous financial support that has made this project possible. Responsibility for views expressed, however, remains with the author.

* Corresponding author.

E-mail addresses: e.foschvillaronga@qmul.ac.uk (E. Fosch Villaronga), agolia@unisa.it (A.J. Golia).
} 
pact assessments in shared data repositories, and using it for evidence-based policies) and to strengthen the legitimacy of standards.

() 2019 Eduard Fosch Villaronga and Angelo Jr Golia. Published by Elsevier Ltd. All rights

reserved.

\section{Introduction}

Due to the novelty of practices and impacts, the development of technology may bring about unclear rules and areas of legal ambiguity (De Hert 2005; George et al. 2012; Vayena and Gasser 2016; Bacon et al. 2017). In other words, there might not be an immediate applicable legal rule or precedent to a particular use or development of technology. The exponential growth of supercomputing power, the ability to store and process large data and improve the performance of the Internet (Butler 2016) do not seem to facilitate either way the reaction capacity of society to face the problems technology may cause. These factors altogether hinder the identification and the addressing of the ethical, legal and societal issues (ELSI) associated with the use and development of technology by governments and public regulatory bodies, who struggle to catch up with technology (r)evolution.

One of the consequences of the inability to keep up with the fast pace of technological innovation in robotics is that the industry, and more generally, private actors, usually takes the lead and develop their standards. This fact has happened in many regulatory fields. In the case of robot technologies, there are already available standards aiming to mitigate the ELSI posed by robotics. In concrete, both the British Standard Institute (BSI) and the Institute of Electrical and Electronics Engineers (IEEE) have developed standards governing the ethical design of robot technologies. Among other consequences, the production of private standards implies a shift in the centralization of regulation, which no longer resides solely on public regulatory bodies but also private ones (Guihot et al. 2017).

The high industry presence in governance does not directly imply that public regulatory bodies disregard technological change and do not take steps toward addressing their implications. Public regulatory bodies also pronounce themselves on the technological advance, although this usually takes places at a more late stage. Early in 2017, the European Parliament released a very pioneer Resolution on Civil Law Rules on Robotics 2015/2103(INL). The European Parliament (EP) called on the European Commission (EC) in considering initiating a legislative procedure governing emerging robotic technologies. In exact words, the European Parliament requested the Commission, based on the Article 225 Treaty on the Functioning of the European Union (TFEU), to submit a proposal for a directive on civil law rules on robotics based on the Article 114 TFEU (ex 65 Resolution 2015/2103(INL) 2017). Far from being a binding document yet, nonetheless, the resolution lacks technical awareness (Fosch-Villaronga, 2019) and, accordingly, contains provisions-including the creation of specific legal status for robots-which can be 'morally unnecessary and legally troublesome' (Bryson et al., 2017).

In this context of multiple regulatory bodies with mismatching interests - one general and public; and the other one specific and private - neither the regulator nor the addressee seem to exactly know what needs to be done (Sabel et al. 2017), although the users' rights might be at stake in any case. This uncertainty is especially intriguing in specific fields of application where robots interact directly with children, elderly or disabled; especially if it is known that robots can cause moral implications (Salem et al. 2015).

In this paper, we first briefly explain the distinction between two different modes of regulation, i.e., standard-setting and law-making, highlighting their respective features and their reciprocal interrelationships, i.e., the related process of regulative "hardening," in particular through the standard juridification processes in section II. The much-debated theoretical issue of the normative and legal nature of standards adopted by private/hybrid organizations-such as the International Standardization Organization (ISO)—is brought to the fore to comparatively analyze advantages and disadvantages of these different modes of regulation. Building on recent robot standards (ISO Standard 13482:2014 on Safety Requirements for Personal Care Robots, BS 8611:2016 "Robots and Robotic Devices. Guide to the ethical design and application of robots and robotic systems" and the IEEE SA 7000 series concerning the ethics of autonomous and intelligent systems) and recent robot regulations (drone, delivery, and autonomous car legislation), succinctly described in Section III, we address the impacts and challenges of overlapping public/private regulatory initiatives governing robotic technologies.

In this paper, we question the sole use of standardsand their mere consequent harmonization-to govern robotic technologies, as these may not provide sufficient protection to end users. We also reflect on how public policymaking could increase their technical understanding of robot technology to devise an applicable and comprehensive framework for this technology.

In light of these reflections and considerations, we propose different ways to integrate the technical know-how into policymaking (e.g., collecting the data/knowledge generated from impact assessments in shared data repositories, and using it for evidence-based policies) in section IV. In this section, we also explain how the systems theory could help strengthen the legitimacy of standards. Section V includes the conclusions and final remarks.

\section{Standard-setting vs. lawmaking}

\subsection{The concepts of 'standard' and 'standardization'}

Before comparing standard-setting and lawmaking, it is necessary to recall two different meanings of standardization briefly. These are explained from a subjective and an objective perspective:

From a subjective perspective, i.e. that of the actor producing and/or adopting the norm, the concept of 'standardsetting' is a form of regulation put in place by organizations 
that, from an institutional standpoint, do not act as politically legitimated bodies, but as either private or hybrid actors, whose legitimation is mainly based on their expertise (Cafaggi 2011). In this regard, an organization may be considered "hybrid' when, although wholly or partially financed by public actors, its governance and its decision-making procedures stay independent from them. Besides the ISO, an international/transnational level other relevant standard-setting organizations are the International Accounting Standards Board (IASB); the Basel Committee on Banking Supervision (BCBS); the Codex Alimentarius Commission (CAC); the Internet Corporation for Assigned Names and Numbers (ICANN).

From an objective perspective, definitions of 'standardization' may vary in each case according to the proper speculative purpose. However, it can be generally defined as any 'activity of establishing, with regard to actual or potential problems, provisions for common and repeated use, aimed at the achievement of the optimum degree of order in a given context'; while 'standard' can be referred to as any 'document, established by consensus and approved by a recognized body, that provides, for common and repeated use, rules, guidelines or characteristics for activities or their results, aimed at the achievement of the optimum degree of order in a given context' (ISO/IEC 2004).

\subsection{Differences between standard-setting and law-making}

Based on the concise definitions indicated above, in a general and abstract way, it would be possible to draw up clear differences between standard-setting and law-making. Indeed, since the beginning of the modern era at least, i.e. since the emergence of the State as dominant political actor, conventionally set with the 1648 Westphalia Peace, law has been conceived as a product of politically (not necessarily democratically) legitimated bodies, which gained the monopoly of legitimate force in a given territory. In other words, according to such normative perspective, only political processes give institutions the legitimation to adopt rules valid and enforceable in respect to all members of a community.

Similarly, and again according to the paradigms of modern era, lawmaking does not necessarily relate to 'the achievement of the optimum degree of order in a given context', but rather to the achievement of consensus and agreement among the relevant (i.e. hegemonic) members of the community on the substantive content of the rules themselves. This consensus and only this consensus legitimates their overall validity, enforceability, and binding nature. This further explains the paradox that in some jurisdictions legal rules may even assume, e.g., that climate change is a 'hoax,' while scientific evidence shows precisely the opposite.

From this perspective, the fact that compliance with standards remains formally voluntary - but we further investigate this claim - is considered as a demonstration that they do not set legally binding rules, and somehow contributes to their confinement to the blurred domain of the so-called soft law, an a-technical phrase generally indicating any regulation considered as not directly enforceable, either for the absence of genuine sanctions, or for its lack of precision (Delmas-Marty 1986 and 1998).
However, this conceptualization closely ties to the abovementioned assumptions of the modern era legal theory. In fact, since the half of the XX century at least, legal systems have undertaken a new type of fragmentation, which is not based on territorial units anymore - as in the Westphalian order - but rather on functionally differentiated units: science, religion or economy. (Luhmann1971). As a consequence of the basically unlimited circulation of information, knowledge and production factors (Strange 1988), such fragments, which lied latent in the legal orders of States in the form of 'social norms', have today fully emerged, and, in different forms and to different extents, have gradually set proper legal systems: lex mercatoria, lex digitalis, lex scientifica, lex sportiva, etc. These latter connect functionally differentiated systems, based on different and irreducible rationalities, and have become transnational, partially freeing themselves from the limits imposed by States' control of territories (Snyder 2003; Fischer-Lescano and Teubner 2004; Catà Backer 2007, 2014). In short, the functional differentiation, together with the processes of globalization, generating a plurality of de-centered transnational legal systems, with their sources of legitimation, which does not only deprive politically legitimated law of its effectiveness but of actual regulatory domains.

\subsection{Intertwinement}

According to what we just argued, setting a clear distinction between soft law and hard law, between standard-setting and lawmaking, is today quite problematic. This is further shown by their intertwinement and reciprocal cross-references, justified by actual and technical needs.

Indeed, standardization is necessary to both private actors (especially enterprises) and States. Transnational enterprises (TNEs) increasingly externalize, so to say, the functions of self-regulation and self-organization to hybrid institutions, for several reasons. First, they gain credibility in the eyes of consumers and, more generally, legitimation towards external actors. Secondly, compliance with standards is often a condition to access specific or protected markets or to take part in public procurements. Thirdly, and most importantly, standardization enables more efficient coordination and cooperation, by reducing uncertainty and transaction costs, and allowing a high degree of technological and productive interoperability (Howard-Grenville et al. 2008; Gunningham et al. 2004; Vesting 2004).

However, in contemporary economic and social context, standardization is even more necessary to States. Indeed, standards perform the fundamental function of regulating transnational phenomena (from finance to fishery, from corporate social responsibility to clinical and technological trials) where States do not manage to reach political agreements, through the traditional forms of binding international law (Fenwick 2013; Kjaer 2013; Renner 2013). Thus, also from the perspective of States, standardization constitutes an example of externalization of functions once exclusively held by them (De Londras 2011). An example is the recent calls of the EP to the EC on harmonizing technical standards (ex 22, Resolution 2015/2103(INL) 2017): 


\section{Standardization, safety, and security}

Highlights that the issue of setting standards and granting interoperability is crucial for future competition in the field of $\mathrm{AI}$ and robotics technologies; calls on the Commission to continue to work on the international harmonization of technical standards, in particular together with the European Standardization Organizations and the International Standardization Organization, in order to foster innovation, to avoid fragmentation of the internal market and to guarantee a high level of product safety and consumer protection including where appropriate minimum safety standards in the work environment; stresses the importance of lawful reverse-engineering and open standards, in order to maximize the value of innovation and to ensure that robots can communicate with each other; welcomes, in this respect, the setting up of special technical committees, such as ISO/TC 299 Robotics, dedicated exclusively to developing standards on robotics.

This means that 'public relevant' functions of transnational regulation are necessarily outsourced to bodies without political and democratic legitimation, which States can influence only to some extent. Moreover, States become in practice more and more dependent on the activity of standardization of hybrid bodies, insofar as it is much more costefficient incorporating into domestic law sources already elaborated and 'used' by the operators, than elaborating new and less effective ones (Callies and Renner 2009). Further, and for the same reasons, abandoning already established standards can be prohibitive for most of the States and their economies (Tully 2007).

In the face of States' marginal influence, standardization bodies and institutions are, on the contrary, much more affected by private actors and TNEs in their respective processes of norm-production. Indeed, these latter are generally based on criteria of accuracy, suitability, adequacy, and impartiality towards the addressees, and foresee forms of consultation, participation and consensus-building as broad as possible among the stakeholders (Cassese 2012). In some cases, such participation occurs informally, without binding mechanisms. However, private actors and producers - especially in the field of new technologies - are normally the only ones to hold the know-how, necessary to the formulation of the standards themselves, as well as the resources necessary to assure a continued participation/involvement, especially when compared to consumers' associations, human rights, NGOs and the governments of developing States (Tully 2007).

All such elements result in a substantial monopoly held by hybrid bodies in some fields of transnational regulation, a monopoly that further diminishes their need of legitimation before non-participating or underrepresented actors.

\subsection{Hardening process}

Having described the reality of standard-setting in contemporary transnational regulation, we can now better understand its importance and centrality. Soft-law is the category usually used for standard-setting. This latter, as we already mentioned above, is a fluctuating and blurred notion, comprising a wide arrange of forms of normativity posited between hard law and non-law. Indeed, especially political sciences theorists tend to conceive 'soft law' as a shorthand term 'to distinguish a broad class of deviations from hard law-and, at the other extreme, from purely political arrangements in which legalization is largely absent' (Abbot and Snidal 2000, 422). However, regardless of purely nominalist issues, only a highly formalistic insight could regard these sources as non-binding: we have seen that complying with them is often much more necessary (to both States and private actors) than with the rules of so-called hard (both domestic and international) law. That is why transnational private/hybrid regulation and standardization puts into question the very divide between hard (i.e., politically legitimated) law and soft (i.e., politically non-legitimated) law, which becomes much more blurred, insofar as these forms of normativity become increasingly autonomous from States (Teubner 1997), and the non-compliance with the principles and rules set in standards may often involve much more serious practical consequences than the violation of hard law. Indeed, as we explain below, the exclusion from 'closed' markets and productive fields, prohibitive interoperability and transactions costs-which often follow the non-compliance to 'private' standards-constitute in most of the cases more effective 'sanctions' than the formally legal ones.

However, how does this reality emerge into the legal world? As we have seen, positivistic assumptions tie the dogmatic tenets of modern law, where the State is the sole rule-maker. Therefore, political law-makers, legal practitioners and judges still need hard-law provisions to give relevance or, more generally, to 'see' private and hybrid regulation (Michaels 2005). This fact leads us to the issue of the dynamic relationship between standard-setting and lawmaking, up to now analyzed from a static perspective.

In general, and for classificatory purposes, such dynamic relationship may be divided into three macrotypes (Michaels 2005): (1) competition/rejection; (2) coordination/delegation/incorporation; (3) deference.

(1) The competition/rejection type, rarer and rarer, occurs when hard-law provisions explicitly forbid or try to substitute standards with different substantive content. In this case, States oppose more or less directly to the very idea of private rule-making in a given regulatory field. One example is the new Regulation 2017/745 on Medical Devices, which extends its scope to devices with both a medical and a non-medical intended purpose. According to the Art. 1.3 of the medical device regulation, these devices "shall fulfill the requirements applicable to devices cumulatively with an intended medical purpose and those applicable to devices without an intended medical purpose." In this case, the lawmaking overrides and rejects the division that the industry had created when they released safety standards for non-medical service robots (personal care robots, ISO 13482:2014) and medical devices (ISO 13485:2016). Today, lower limb exoskeletons for rehabilitation, activities of the daily living or industrial applications have to comply with the medical device regulation cumulatively.

(2) More often, especially in the EU regulatory framework (Senden 2005), the relationship between standards and law is based on coordination/delegation/incorporation, which 
in turn takes different forms. In general, hard-law provisions set general principles in a given regulatory field, leaving to private/hybrid bodies the task to adopt detailed technical rules. The public regulator may set an entire discipline (both principles and details), only applicable in the absence of detailed standards. Giving such power to standards could lead standards to derogate whatever the public regulator has established. Further, State law can even incorporate standards into the domestic legal system, with explicit provisions. The coordination/delegation/incorporation type aims to promote forms of 'controlled' or 'regulated' self-regulation by private/hybrid actors (Braithwaite 1982; Ayers and Braithwaite 1992). More generally, what we classify as coordination/delegation/incorporation comprises all the cases where States are willing to accept, for different reasons, some degree of autonomy by private actors but still wanting to somehow control them from the outside (Hennebel and Lewkowicz 2007). One example is the Machinery Directive 2006/42/EC, which includes some provisions referring to the presumption of conformity with the directive if harmonized standards have been followed (Art. 7 Machinery Directive).

(3) Finally, deference occurs, especially in particularly new regulatory fields such as robotics, artificial intelligence and new technologies in general, when a hard law provision does not refer to standards nor makes them unlawful. In these cases, the politically legitimated law does not 'see' directly standards legally, but it rather reduces them to 'facts.' In such cases, it is the judicial practice to let them emerge and to set up a de facto 'inter-normativity' or 'interlegality' among legal systems (Delmas-Marty 2006; Zumbansen 2011; Teubner and Korth 2012; Jurčis et al. 2013). For example, judges may resort to the concept of good faith and fairness in the implementation of a contract, or in a tort dispute. Further, they may use the concept of 'best practices' in a given field, to which both criminal and civil law provisions often refer. These provisions, used in this way by judges, work exactly as renvoi, i.e., as norms permitting the application of a rule belonging to a different legal system. Thus, regardless of their appearance and nomen iuris, concepts such as good faith or best practices become the entry points of private/hybrid functional systems into political systems (Teubner 2004). It is apparent that deference occurs when States are not willing (or are not able) to impose even minimum constraints to standardsetters, with the result that the burden of the decision concerning the 'entry' of standards, falls almost entirely on judicial bodies, with the consequent expansion of the power of these latter and, more generally, of judge-made law (Delmas-Marty 2007; Teubner 2002). Further, and conversely, deference involves the maximum degree of autonomy by private/hybrid regulators, which are not called to abide by even the most general politically-legitimated principles, except for the public policy and mandatory rules, in those jurisdictions where these latter constitute a bar to the recognition/enforcement of contracts.

To sum up, in these different types of dynamic relationship States have the opportunity to influence, affect and 'irritate,' so to say, both the substantive content and the legitimacy of standards and private/hybrid regulation, to push them to internalize non-technical rationalities. In one sentence: to contribute their (internal) re-politicization (Teubner 1998; Bomhoff and Meuwese 2011).

\section{Recent regulatory developments for emerging robot technologies}

In the previous section, we have recalled the general issues concerning the standard-setting/lawmaking divide, this section addresses more specifically the challenges and miscommunications between the robot and the regulatory development, especially within the private-setting and public policymaking dichotomy.

Regulation is complicated on many occasions (Hutter 2016). Regulating something usually entails the interaction between four constraints: the architecture of what needs to be regulated, the social norms surrounding the area where the thing is, the rules of the market (offer and demand) and the law (Lessig 2006). In general terms, the plurality and the de-centeredness of transnational legal systems, all the unknown risks of the regulated field, or all the unforeseeable impacts of a hard-law instrument stand in the way of regulation (Shelton 2003). Concerning emerging robot technologies regulation, other factors such as the autonomous behavior of robots, trigger its complexity even more. Indeed, although not all robots are autonomous systems, those autonomous operate with very little human control, perform a task differentiating between different contexts of use on their own, and alter their behavior accordingly without human intervention. The autonomy of robot technology challenges the application of traditional metric-threshold-test regulatory frameworks (Danks and London 2017), and the understanding of how could these systems be regulated.

Another critical factor limiting regulation is the speed with which robotics advances, which significantly hinders the understanding of the need to create technology-specific, long lasting benchmarks. Developing a hard law at early stages of the development of a robot may make little sense because its associated impacts might be unknown. What's more, it might not even be clear whether the robot enters the market, or whether it is left aside like many other lab experiments. The mere application of guidelines at a more mature development stage may lead to under-regulation. These uncertainties on when do we have to regulate technology have been already pointed out in the literature under different names: the Collingridge dilemma (Collingridge 1982), the 'regulatory trilemma' (Teubner 1987), or recently called the pacing problem (Marchant, Braden and Herkert 2011). Beyond a possible regulatory capture and the enforceability battle between the nature of the regulatory instruments (standards vs. hard law), these dilemmas lead to a step-back problem, that is: how to identify the need to generate guidelines for new technologies in the first place, and how, when and what content is deemed appropriate for such technologies (Fosch-Villaronga and Heldeweg, 2018).

While these factors might challenge public regulatory initiatives, this is not usually the case for private setters, who 
have already developed standards for robot technologies. In the following sub-sections, we compile industrial standards for robot technology (service robotics, and the ethical design of robot technology). We also compile recent pieces of legislation covering drones, self-driving cars, delivery, and healthcare robots to illustrate the dissonances between public and private regulatory initiatives.

\subsection{Service robot standards}

Before 2014, there was not any standard that governed the use and development of service robots. Previously, robot standard regulation focused mainly on industrial robots, a robot type that traditionally had minimal interaction with humans, and that performed repetitive tasks in well-defined environments. For these reasons, private standards (mainly ISO 10218 Robots and robotic devices, Safety requirements for industrial robots, Part 1 and 2) ensured safety by separating the robot from the human operator fencing the robot and reducing to the maximum level the human-robot interaction (Fosch-Villaronga and Virk 2016). This standard integrated into the European legislative framework via the Machinery Directive 2006/42/EC.

The introduction of collaborative robots in the workplace that closely interact with humans (also called co-bots), and the exponential growth of service robots, however, makes one wonder whether industrial standards address the issues arisen by robots outside the industrial environment or not. Service robots are designed to interact directly with the general public and to perform tasks in multiple and not predefined scenarios, like the household or the public space. These robots call for different safety strategies because they interact with non-expert users in different ways: physical passive contact (robotic wheelchairs), physical active contact (by attachment to the users' bodies like exoskeletons), indirect contact (drone technology) or socially (socially assistive robots, cognitive therapeutic robots) (Fosch-Villaronga 2017). Yet, current European Harmonized Standards do not cover areas such as automated vehicles or machines, additive manufacturing, collaborative robots/systems, or robots outside the industrial environment (Simmonds et al. 2017; SpiliopoulouKaparia 2017), and this leaves manufacturers without knowing to what standards they have to adhere to ensure their robots are safe.

The following sub-sections collect recent standard setting initiatives that govern the use and development of service robots. The first sub-section is about the ISO 13482:2014 Safety Requirements for Personal Care Robots and the second explains the rise of robot ethical standards, including the BS 8611:2016 and the IEEE Ethically Aligned Design initiative.

\subsubsection{The case of ISO 13482:2014 on personal care robots}

Personal care robot research has been going on for a couple of decades now. In the 1990s, some groups where developing voice-controlled robotic wheelchair (Stanton et al. 1990; Miller and Slack 1995), others focused on arm exoskeletons (Bergamasco, et al. 1994; Caldwell et al. 1995), and researchers at MIT were working social robots that would be used for care applications in the future (Breazeal and Scassellatti 1999).

Although this research was rapidly evolving, it was not until February 2014 that the ISO presented a technical frame- work. This framework was on the safety requirements for personal care robots (ISO 13482:2014), that is, for those 'service robots that perform actions contributing directly towards improvement in the quality of life of humans, excluding medical applications' that '[...] might include physical contact with the human to perform the task'. Instead of fencing the robots of the humans to ensure safety, this standard addresses the physical human-robot interaction hazards by stipulating safety requirements on several design factors such as robot shape, robot motion, energy supply, and storage or incorrect autonomous decisions. The standard represented a step forward in the provision of minimum safety requirements for this type of service robots, which was at that time lacking. Still, the framework, had some limitations (Fosch-Villaronga 2015; Fosch-Villaronga and Virk 2016). 'Personal care' was not defined throughout the standard. Instead, some examples of personal care robots: person carrier, physical assistant and mobile servant; and the statement 'future editions of this International Standard might include more specific requirements on particular types of personal care robots, as well as more complete numeric data for different categories of people (e.g., children, elderly, pregnant women)' was included. With no other information, this statement conveys the impression that the standard is a temporary benchmark and that there should be in place special requirements for different types of users. This brings about uncertainties with regards to what is the protected scope of the framework, as it could be that a personal care robot is certified under the standard without having taken into consideration any special safety requirements for different types of user. Can pregnant women use lower-limb exoskeletons? Should producers establish special safeguards for overweight patients? Can epileptic patients use mobile servant robots?

The standard is concerned with the physical aspects of the human-robot interaction. However, and as we mentioned, we interact with personal care robots in many various ways: physically passive or active (including attached to the body), and cognitive (if robots are meant to interact with the user socially). If 'mental communication and emotional contact are established between the robot and the person' (Rodić et al. 2016), and if robots may cause psychological harm (Resolution 2015/2103(INL) 2017), applying physical safeguards might be essential but may not suffice to provide comprehensive protection to the user. At the moment, however, there is little research on cognitive or psychological harm, although it seems to be significant if the main channel of interaction between the user and the robot happens at the cognitive level (FoschVillaronga 2016).

The standard disregards the cognitive aspects. Certified and perceived safety are two different things (Salem et al. 2015). Following standards can guarantee and certify safety, but it is more challenging to address perceived safety as this refers to the perception of the subject/user of a robot. This perceived safety can happen at the physical level, for instance in light of fear of falling during the rehabilitation with an exoskeleton (which completely constraints the correct performance of the device); but also at the cognitive level, for instance, fear of suffering from a psychological risk after long-term robot usage in neurorehabilitation. Knowing that the law protects the physical and the mental integrity, this 
standard falls short in addressing different issues arising from the human-robot interaction (something already highlighted by the EP).

Semantic confusions are also present in the standard. For instance, the use of the term "wheeled passenger carrier" is misleading, as instead of a person carrier robot category it seems it is referring to wheelchairs (Fosch-Villaronga and Roig 2017). Wheelchairs are medical devices and, thus, they have to comply with the medical device legislation. The Art. 1.3 of the new regulation for medical devices reinforces this idea by extending the scope of the regulation to devices that present similar characteristics.

While ISO 13482:2014 is concerned with physical safety requirements, the legislative system includes many other fundamental rights to be protected. The euRobotics projects on the legal and ethical aspects since 2010, and the European Robolaw project have repeatedly highlighted that robots raise legal and ethical questions with regards to (1) health, safety, consumer and environmental regulation; (2) liability; (3) intellectual property rights; (4) privacy and data protection; and (5) capacity to perform legal transactions. These findings highlight that, available industrial standards that establish safety requirements for service robots deployed in personal care, are not offering enough protection to users.

\subsubsection{The rise of robot design ethical standards}

Service robots in sensitive contexts such as healthcare facilities perform tasks in close contact with users that could be elderly, children or infirmed people). In such cases, robots could compromise not only safety but also other aspects such as privacy, dignity or autonomy. Indeed, robot technology can have by-product moral implications (Salem et al. 2015) such as a loss of human contact, reinforcement of existing socioeconomic inequalities or failure in delivering good care. Failing to accommodate such concerns could harm users in concrete, and the society at large.

The existence of such concerns may directly derive from the little awareness of the consequences of the use and development of robot technology in different areas. This is exacerbated by the tardiness of the legal system in providing greater regulatory clarity, effectiveness, efficiency and/or legitimacy for new developments, which usually is torn between the need to establish new rules or not (moreover, it is not an exception in the case of robot technology) (Fosch-Villaronga and Heldeweg 2018). In these cases, the industry bets for filling such regulatory gap with standards. In the case of robot technology, private actors have developed standards that incorporate other aspects than safety. The clearest examples are the British Standard (BS) 8611:2016 "Robots and Robotic Devices. Guide to the ethical design and application of robots and robotic systems" and the IEEE Ethically Aligned Design from the IEEE Global Initiative and Standard Association.

The BS 8611:2016 identifies twenty moral hazards and risks grouped on societal, application, commercial/financial and environmental categories, and provides guidelines to mitigate or reduce risks associated with these categories to an acceptable level. The standard provides engineers with the tools to conduct an ethical risk assessment. Although created ex novo, these guidelines are built on existing safety requirements for industrial, personal care and medical robots.
The IEEE initiative was born "to ensure every technologist is educated, trained, and empowered to prioritize ethical considerations in the design and development of autonomous and intelligent systems" (IEEE Ethically Aligned Design 2016). While some researchers have already pointed out that concepts such as 'privacy' cannot be hardcoded (Koops and Leenes 2014), the standard has an entire section on how to promote the embedment of values into autonomous intelligent systems. Other sections include general principles, methods to guide ethical research and design, safety and beneficence of artificial general intelligence and artificial superintelligence, personal data and individual access control, the reframing autonomous weapon systems, and economic/humanitarian issues.

Although these standards could be a first step in providing a comprehensive framework to address multi-faceted risks associated with robotic technologies, they raise two important questions, one being whether standards should cost money, and the other being whether the decentralization of standard makers promotes safer or less safe common safeguard baseline. While the IEEE Global Initiative document is for free, the BS has a member and a non-member fee. The same happens with ISO standards. This phenomenon conveys the impression that the (soft-)Law is being privatized (Fosch-Villaronga and Roig 2017). If the more and more we rely on standards (because they can externalize essential functions), should they continue being offered for a price? Concerning the second question, the EC enounced in 2017 that 'manufacturers and other economic operators are free to choose any other technical solution that proves compliance with mandatory legal requirements' (EC Harmonized Standards 2017). Covered in an openness veil, this could entail diversity on risk assessment criteria, the responsibility of which does not fall under the certification agency. Do all ethical standards offer enough protection to users?

\subsection{Legislative developments of robot technology}

In light of the exponential growth of service robot technology, a discussion on the pros and cons of private setting is insufficient. This discussion needs a parallel overarching legal design analysis of the dynamics of regulation on robotics, and an exploration of different options for enhancing an open structured regulatory approach that takes into account more aspects than jus safety at the public policymaking level.

This section introduces a collection of recent regulatory developments from the public policymaking governing different types of robots. The majority of the existing laws revolving around robots and artificial technologies focus on drones and self-driving cars, although there are recent examples of laws for delivery robots. At first glance, these specific-robot laws seem to reinforce the idea that there is the need to give clarity and a legislative response to certain types of technology, including what are the consequences for non-compliance. They also suggest that general all-embracing-robot-type rules may not suffice to provide an adequate response to robot developers and, in consequence, to protect the rights of the users. Still, a closer look to the provisions reveals ambiguities and dissonances with the state of the art of the technology that does not 
necessarily provide greater clarity and legal certainty than the standards governing robot technology.

\subsubsection{European initiatives to regulate robot technology}

As mentioned in the introduction, in February 2017 the European Parliament released a very pioneer Resolution on Civil Law Rules on Robotics 2015/2103(INL). The resolution included general remarks on legal issues such as liability, insurance, intellectual property, safety, and privacy; different types of robot applications such as care robots, medical robots, drones, and autonomous cars; and it also covered different contexts of use and social aspects, for instance, unemployment, environment, education, social division, and discrimination.

The EP postponed the task of defining what a 'smart robot' in the legal domain, although it identified indissociable aspects of robot technology like the capacity to (1) acquire autonomy through sensors and/or by exchanging data with its environment (inter-connectivity) and the analysis of those data; (2) learn through experience and interaction; (3) adapt its behaviors and actions to its environment. The EP also highlighted that robots have physical support. In a follow-up document, the EC was uncertain on whether a definition for the concepts 'cyber-physical system', 'autonomous system' or 'smart autonomous robot' was necessary for regulatory purposes (EC Response to the Resolution 2015/2103(INL) 2017).

Although this resolution represents one of the first public policymaking efforts to address the uncertainties revolving around the use and development of robot technologies, this lege ferenda raises some concerns:

- There are some references to science fiction, including Laws of Robotics (referring to Asimov's laws) that 'must be regarded as being directed at the designers, producers, and operators of robots, since those laws cannot be converted into machine code';

- EP defined robot's autonomy as 'the ability to take decisions and implement them in the outside world, independently of external control or influence,' which suggests the possibility to have a responsibility gap for the autonomous actions of robot technology (Johnson 2015);

- Assuming that there is a responsibility gap, the EP proposes the creation of special legal status for robots, and apply electronic personality in certain cases;

- The identification of the (possible) decrease of humanhuman interaction after the introduction of care robots, with a complete disregard of the fact that care robot users might be already alone, that they may want to be alone (e.g. when they need to be fed, or cleaned), or the fact that robot technology could be a bridge between humans;

- The introduction of the concept of reversibility, which refers to "the ability to undo the last action or a sequence of actions allows users to undo undesired actions and get back to the 'good' stage of their work" but that it could be difficult to apply in cyber-physical environments;

- The creation of an insurance schema revolving around robot technologies, without stating which robots should deserve insurance.

The EC responded to the resolution by saying that they need to analyze the issue more in depth before giving a more detailed response. The EC agreed on the fact that legal uncertainty concerning civil law liability may affect the development of robot technology negatively. In this respect, they have launched an evaluation of the Directive 85/374/EEC on Liability for Defective Products to increase legal certainty around the allocation of liability. The Commission argues that robots involve a physical/machinery part and complex software systems, and determining who is liable in such ecosystems is difficult (EC Response to the Resolution 2015/2103(INL) 2017).

The EC states that much more analysis is required to determine what constitutes a robot or not, and agrees that an insurance schema needs to careful consideration. The Commission pushes towards the creation of new testing regimes including piloting, modeling, simulation, and virtual testing because old tests might not be sufficient to determine whether a robot is safe or not. However, even if robot technologies may need new testing zones, machine learning capabilities, in particular, reinforcement learning, may challenge the effectiveness of such testing zone, as the robot might continue learning after its insertion in the society. Indeed, machine learning capabilities may create, over time and depending on how they learn from experience, robots that are unique. Having many robots, evolving in different directions might challenge certification processes (the certified safety we were referring before). This uniqueness might lead to the creation of robots that behave imperfectly, i.e., robots that are not compliant one hundred percent to their pre-set rules. In the words of Konok et al. (2018), these robots may end up being unique, disobedient and imperfect, which can affect their trust and reliability. Do we want as a society to have non-compliant robots whatever the reasons for that may be? If yes, should they be tested in a controlled environment? Would the society be O.K. having a robot that ends up behaving like Tay? ${ }^{1}$

\subsubsection{Self-driving cars legislation}

Removing human drivers from the road accident equation and providing mobility options for elderly and impaired people are the main reasons for developing self-driving cars. Self-driving cars incorporate an autonomous system capable of performing all aspects of the driving task without a human driver. Some regulations even state that such autonomous system 'will not at any time request that a driver assumes any portion of the dynamic driving task when the automated driving system is operating within its operational design domain' (GA S 219 2017). To perform such task, vast amounts of data, including user's data, need to be collected and processed. International policymakers from Japan, US, and EU have already drawn attention to this issue (Japan Draft Rules 2017; Pillath 2016; NCSL 2017).

Existing laws, however, did not conceive the possibility to have driverless cars. Not even the most recent amended version of the Convention of Vienna has contemplated such a possibility, as it still requires in every vehicle a human driver (ECE/TRANS/WP.1/145 2016). Some countries have decided to address this gap through the development of legislation directed toward the addressing of the challenges arisen by driverless cars. The National Conference of State Legislatures

${ }^{1}$ Cfr.: https://www.theverge.com/2016/3/24/11297050/taymicrosoft-chatbot-racist. 
(NCSL) database, for instance, contains all the enacted legislation concerning autonomous vehicles in the United States (NCSL 2017).

In European territory regulatory initiatives are less present. It seems Europe is not very keen on establishing rules for technologies not yet applied (Pillath 2016), although there are some examples touching upon self-driving cars: a German law that allows the testing of self-driving cars on public roads, or the Vehicle Technology and Aviation Bill of the U.K. that aims at modernizing the vehicle policies. Europe, however, requires harmonized approaches to avoid fragmentation, which could impede and jeopardize European competitiveness. Disparities among legislations, in fact, are what lead NHTSA state the importance of delineating Federal and State regulatory responsibility scheme for motor vehicle operation. The main problem of USA lied on how to add or amend State authority on autonomous driving systems, suggesting that it should only be NHTSA to write about safety design and performance aspects of autonomous driving systems (NHTSA Best Practices for State Legislatures 2017). In this respect, Japan is drafting legislation on self-driving cars because they seek to develop this technology for the Olympic games in 2020 (Japan Drafts Rules for Autonomous Vehicles 2017).

Although there is no global and general agreement of the content of the topics that involve the development and use of self-driving cars, legislation tends to cover the same topics: definitions, insurance and liability, operation on public roads, privacy of collected vehicle data, cybersecurity of the vehicle, vehicle inspection and testing, licensing and registration, and operator requirements among others.

A novelty and a positive aspect of self-driving cars regulations is the inclusion of the data protection and cybersecurity angles. Indeed, these vehicles can generate, collect, transmit personal data such as favorite music, preferred places or routes, home/work positions or routines, which threatens data protection (Pillath 2016). Associating self-driving cars with informational privacy-related threats is essential because a cybersecurity threat to an autonomous vehicle could jeopardize the safety of the passengers at an unprecedented scale.

There are, however, some disparities and dissonances in the legislation. In the State of New York, for instance, strict liability is for manufacturers, owners and operators of unmanned motor vehicles (NY A 7243 2017). In Georgia, the users of a self-driving car do not require a driving license (GA S 219 2017), but in Japan, autonomous car testing is only allowed if the driver has a driving license is in charge (and who would be held responsible in the event of an accident). At some point, NHTSA said that they would identify the artificial intelligent (AI) system of the car as the driver. Today it is uncertain who would be liable in case of a car crash on their website (NHTSA Website 2018).

\subsubsection{Drone technology legislation}

Although they have received several names, including Unmanned Aerial Vehicle (UAV) or Unmanned Aircraft System (UAS), 'drone' is the common word to refer to pilotless aircraft remotely controlled or on autonomous navigation mode. Drones have typically operated in the military field for surveillance and attacks. The industry found a niche in the market and has recently developed drones for civil uses, including parcel delivery, agriculture, inspection, surveillance, search and rescue, and lately for picturing and filming.

The Convention on International Civil Aviation states that existing rights and obligations apply equally to manned and unmanned civil aircraft (ICAO 2011). However, the Riga Declaration declared that these drones are new types of aircraft not to be confused with airplanes or other types of aircraft and that, in consequence, they needed to be treated with proportionate rules based on the risk of each operation. The Riga Declaration advocated for a risk-based regulation (Riga Declaration 2015). In August 2016, the European Aviation Safety Agency (EASA) adopted a regulation that, although still being a prototype, aims at regulating UAS in an operation-centric, progressive and risk-/performance-based manner (EASA Prototype Regulation 2016).

The fact that EASA is concerned with airspace and outdoor regulations, however, indoor drones (warehouse drones for instance) or even new applications of drone technology (like the sex drones) could be left out of the regulated scope. Moreover, this regulation fails in integrating all the aspects revolving around the operation of drones for civil uses: safety (Clarke and Lyria 2014) privacy (Calo 2011; Cavoukian 2012) or broader aspects such as responsibility, liability and insurance, data protection, societal impacts, acceptance or ethics (Boucher 2015). Failing to integrate all these aspects in regulation could lead to legal uncertainties with regards to the applicable safeguards, and leave consumers/users unprotected.

\subsubsection{Delivery robots legislation}

Autonomous delivery robots are a clear example of how technological developments give rise to legislative gaps. Also called electric personal delivery devices, personal courier, or unmanned sidewalk delivery robots, these robots transport property along sidewalks, shared-use paths or crosswalks in a semi-/autonomous manner. Manufacturers claim that a person can get any good at any time - depending on user's preferences - in a very securely manner (Starship 2017).

These robots did not fit into the existing vehicle categories, not even within self-driving cars, and that is why different states in the United States passed state laws to govern them. Virginia was the first state to legislate on electric personal delivery devices in 2017 (House Bill 2016).

Although the laws might slightly differ among them, they tend to define weight limit, maximum speed, allowed technology incorporated into the device. They also cover co-existing common rules: devices shall operate safely in order not to endanger pedestrians or traffic, do not carry hazardous materials (substances and waste), include visible contact information, and that they need to obey all traffic regulations, including yielding the right-of-way to any pedestrian. These laws typically allow the robots to operate in the state territory unless prohibited expressly. Although the provisions may not be technical or directly applicable, they are quite concrete.

A dissonant provision in the Virginia legislation relates to the concession of rights and duties to the delivery robots. Last paragraph of § 46.2-904 HB 2016 reads 'an electric personal delivery device operated on a sidewalk or shared-use path or across a roadway on a crosswalk shall have all the rights and duties of a pedestrian under the same circumstances.' 


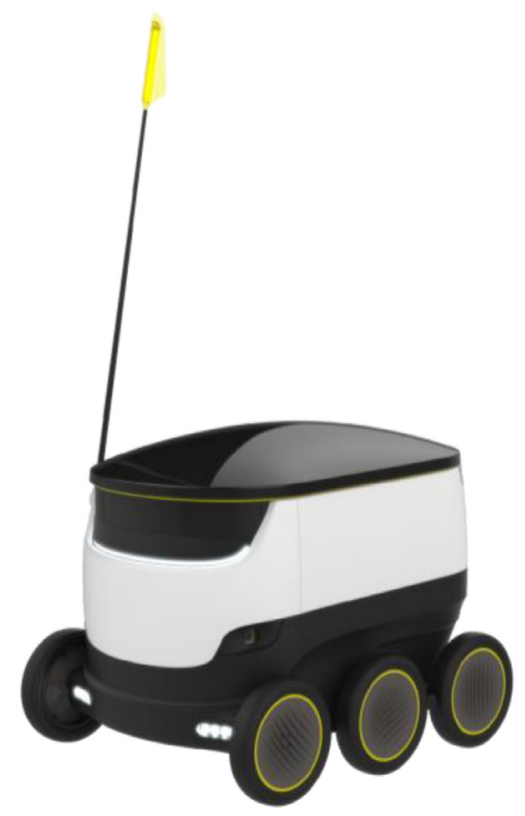

Different scholars have discussed the concession of rights to autonomous agents, often comparing it to the concession of rights to animals or corporations (Laukyte 2013; Darling 2016) or electronic agents (Teubner 2006; European Parliament Resolution 2017). At this point, it is uncertain what status or -hood (personhood, robothood, agenthood) robots should receive. The EP has recently suggested the electronic person fit best in this discussion, although it has been primarily criticized (Bryson et al. 2017).

As that provision $\S 46.2-904$ gives the same rights as pedestrians to the riders of bicycles, electric personal assistive mobility device, motorized skateboard or foot-scooter, motordriven cycle, or an electric power-assisted bicycle on a sidewalk; it seems to imply that delivery robots, riders of such devices and pedestrians shall have the same rights and duties.

Another dissonant piece of information can be found nevertheless along the lawmaking process. Whereas stakeholder involvement in policymaking is found to be crucial, this process needs to objective, open, and transparent, which is not always the case. The Estonian delivery robot company Starship helped the State of Virginia write their law on delivery robots. Having only one voice in robot law negotiation process may lead to tailored legislation that only benefits a few (Glaser 2017).

\subsubsection{Healthcare robots legislation}

The European Commission's Robotics for Healthcare Roadmap defines the healthcare robot domain as 'the domain of systems able to perform coordinated mechatronic actions (force or movement exertions) on the basis of processing of information acquired through sensor technology, with the aim to support the functioning of impaired individuals, medical interventions, care and rehabilitation of patients and also to support individuals in prevention programs.' The areas of innovation related to this domain are medical intervention, supporting professional care, preventive therapies and diagnosis, assistive technology and rehabilitation treatment.
Healthcare robots come in various forms, including robot toys used as medical devices, upper-/lower-limb exoskeletons, surgery or social robots. There are currently no particular laws for healthcare robots more than the medical device regulation. Legislatively talking, this is a relevant example of the competition/rejection type we explained before, i.e., when private standards have no influence over lawmaking nor can overpower it.

ISO 13482:2014 was born with a clear intention to move away from the medical legislation. The standard included 'physical assistant robots,' commonly called 'exoskeletons' for activities of the daily living, which in theory were non-medical devices because they were not for rehabilitation purposes; 'wheeled passenger carriers,' which were not wheelchairs, and mobile servant robots that are not medical devices but they are therapeutic (Fosch-Villaronga and Albo-Canals 2015; Fosch-Villaronga 2016). This standard pushed the industry to have two types of devices, the medical and the non-medical version of different types of robots. For some time, companies wanted to get an advantage of this dual category to get certified through the personal care certification, which presented more relaxed requirements than the medical device certification.

As we mentioned, the newly adopted Regulation 2017/745 for medical devices on its Art 1.3 extends the scope to those devices that have a medical and a non-medical purpose. Although this provision was conceived for other objects, for instance for contact lenses and colored contact lenses, it seems logical that those robots that have a medical and non-medical version but that they might present similar risks to the user (HAL exoskeleton from Cyberdyne for instance) ${ }^{2}$ have both to comply with the medical device regulation cumulatively. Overlooking the medical device regulation in these cases would entail an infringement of the law.

The Art. 12 of this piece of legislation also notes that 'devices which are also machinery within the meaning of point (a) of the second paragraph of Article 2 of Directive 2006/42/EC of the European Parliament and of the Council shall, where a hazard relevant under that Directive exists, also meet the essential health and safety requirements set out in Annex I to that Directive to the extent to which those requirements are more specific than the general safety and performance requirements set out in Chapter II of Annex I to this Regulation.' This is very important because, although ISO 13482:2014 followed ISO 12100:2010 on safety machinery, the European directive on machinery (Directive 2006/42/EC of the European Parliament and of the Council of 17 May 2006 on machinery) dates back to 2006, and does not include any update concerning the ISO from 2010 or the one about personal care robots of 2014. This misunderstanding could lead to a regulatory gap already identified in the literature (Holder et al. 2016; Calo, Froomkin and Kerr 2016).

\footnotetext{
${ }^{2}$ See the non-medical type robot (certified by ISO 13482:2014) here: https://www.cyberdyne.jp/english/products/fl05.html; and the one for medical purposes here: https://www.cyberdyne.jp/ english/products/LowerLimb_medical.html.
} 


\section{How to strengthen the legitimacy of standards and the power of lawmaking}

Although in a different direction, and addressing different aspects, both private setting and public policymaking have recently attempted to govern service robot technology. In the previous sections, we have compiled some examples of the most recent initiatives, and have identified strengths and weaknesses. Seeing the topic complexity, the fastness of the technological change of robots, and the internationality of the subject, we support the idea of establishing a greater collaborative effort between private setting and public policymaking. In this section, therefore, we make different policymaking proposals aimed at strengthening the efficacy and the legitimacy of the current framework of robot regulation.

The proposals are based on two main structural assumptions:

(a) State law (which we also referred to as 'hard law' or lawmaking) cannot fully cope with the lack of expertise and the transnational dimension of robot regulatory field;

(b) Just like in other regulatory fields, robot standards adopted by private/hybrid bodies (which we also referred to as 'soft law' or standard-setting) do not take enough into consideration non-technical (namely, ethical) needs and rationalities and, more generally, do not enjoy legitimacy outside the circle of the involved industries.

Thus, this section aims at answering the following crucial issues: how can we devise a comprehensive but applicable protective framework for healthcare robots? How can we favor the internal re-politicization of standards without having colonization by consensus-based rationality?

\subsection{Theoretical framework: a systems theory approach}

In order to answer these questions, we will mainly resort to the systems/autopoiesis theory approach, which looks at private/hybrid standards as the points of emergence of autonomous legal systems coupled with non-political (in our case, scientific/technological) rationalities (Teubner 1993; Ladeur 1999; Febbrajo and Harste, 2013). Based on sociological analyses, such approach takes as a fact the reciprocal incommensurability of political and non-political discourses/rationalities (Teubner 1997), and the plurality of transnational normative orders (Kjaer 2010, 2013; Catà Backer 2011, 2014), and its policymaking proposals are put forward accordingly. In particular, it aims to stimulate the internal translation of external (political-legal) impulses by autonomous functional systems. In other words, hard law regulations and judicial practice should (and could) not impose politicallydriven ends to private/hybrid actors directly, but rather operate indirectly, so that the inner processes of autonomous functional systems are pushed to reflexively adapt themselves to the demands of their social environment (Teubner 1983,1993; Fischer-Lescano and Teubner 2004).

Such influences, which compel international and transnational standard-setters to engage in learning adaptation, without replacing them, should in turn be based on two equally necessary elements: (1) changes in cognitive structures; (2) pressure directed at achieving this. 'Otherwise, the demands from society will remain ineffective external impulses' (Teubner 2012, 93-94).

(1) On the one hand, change in the cognitive structures refers to the institutional mechanisms through which a functional system 'learns', 'rebuilds' and 'translates', according to its own rationality, external impulses. In other words, while States and political rationality cannot substitute themselves to science and knowledge gaps, they can intervene on the skeleton, so to say, through which such autonomous rationality operates, forcing this latter to reflexively adapt itself. This means 'irritating' a rationality based on science with rationalities coming from (transnational) civil society's politics. Just as an example, in the field of robot regulations the institutionalization, through adequate means, of the participation of third-party organizations and affected outsiders (consumers, users, patients) in the internal deliberative processes of private regulators. The IEEE Global Initiative and Standard Association have followed this initiative in their "Ethically Aligned Design" report by integrating different experts within the writing process of the standard.

(2) On the other hand, pressure refers to both legal and nonlegal sanctions, coming from both traditional hard law enforcement and civil society, i.e. protest movements of NGOs, trade unions, non-profit organizations, professions and public opinion. Once again, here the role of the State, which still holds the power structures (Strange 1998), is crucial, insofar as it introduces instruments to potentiate such pressures and channels societal 'communicative energy'. Here again, we could point to some examples: introducing specific (either individual or collective) causes of action towards actors and industries that do not abide by the ethical standards to which they declare to 'voluntarily' adhere; periodically publishing public 'shame lists' of the industries that do not adhere to ethical standards at all, or denying them access to public procurements, or even licenses to operate. This policymaking approach involves also judicial bodies, which are given a quite activist role (Teubner 1997). In other words, especially when legislative and statutory law does not help or stays silent - as it happens in the 'deference' type of interaction - judges may take into account the social consequences of their rulings, and further exploiting available general clauses, e.g. in contract law (Beckers 2016). Thus, just as example, the adhesion to a standard developed by private/hybrid bodies may be used in a trial or a lawsuit as exemption from responsibility covered by 'good faith' or 'best practices' only on the procedural condition that such standard is elaborated with the participation of the 'affected outsiders', or that its substantive content respects the fundamental values standards requested by domestic constitutional law or international human rights law (e.g. human dignity). 


\subsection{Proposals for better standard-lawmaking intertwinement}

Based on the abovementioned theoretical references, this section compiles different proposals that could enhance both the legitimacy of standards and the technical awareness of public policymaking.

4.2.1. Proposal 1: integrating the generated knowledge of impact assessments into policies via shared data repositories After much research on the topic (Wright and De Hert 2012; Wright 2013; Wright et al. 2013), the data protection impact assessment (DPIA) has become a binding requirement after the General Data Protection Regulation entered into force in 2018. DPIA is an instrument to assess the impact of technologies on personal data (Art. 35 GDPR). There are some standards offering guidance on how to conduct such assessment (ISO/IEC 29134:2017 Guidelines for Privacy Impact Assessment), and there is a rise of different tools that might help to automatize this process (Coles et al. 2018). ${ }^{3}$ Similarly, the Consumer Product and Safety Commission of the US have developed a tool to ease the compliance process of new products called "Regulatory Robot." 4

Still, impact assessments in the legal domain are currently seen merely as an accountability tool, i.e., a way to show that, for instance, a roboticist is compliant with the data protection legal framework (A29WP Opinion 3/2010). In the future, policymaking could take advantage of the data/knowledge generated by accountability instruments, mainly if this process can be automated. The generated data/knowledge could be inserted in a shared data repository to help evidence-based policymaking in matching different types of technology, with threats and risks, and also with mitigations (Notario 2015; Fosch-Villaronga and Heldeweg 2018).

Nowadays, conducting an impact assessment fulfills an accountability function, which law enforcement and compliance purposes use. The knowledge generated by these impact assessments does not feedback the legal system per se nonetheless. In this sense, there is no data collection mechanism oriented towards a repository format for evidence-based policymaking purposes. In other words, the law does not learn from these assessments (yet), they are just standalone and static instruments (Fosch-Villaronga and Heldeweg 2018).

A mechanism that could extract relevant knowledge from these accountability tools could help to build evidence of what technologies exist, what risks arise, and how these risks are mitigated (Fosch-Villaronga and Heldeweg 2018). The policymaking process could benefit from this meaningful technical information, and release guidelines from time to time (Notario 2015). Creating such mechanism would involve having access to companies' impact assessments, building a data repository to which relevant policymakers would have access (data protection authorities, city councils, or agencies, like the European Robot Agency if it ever exists), and spend resources in the processing of all this data. This complex process might

\footnotetext{
3 Cfr.: https://www.cnil.fr/en/open-source-pia-software-helpscarry-out-data-protection-impact-assesment.

4 Cfr.: https://www.cpsc.gov/Business-Manufacturing/ Regulatory-Robot/Safer-Products-Start-Here.
}

take a lot of time and resources at the beginning, but online platforms allow easy information retrieval and leave room for automation. So it is not difficult to imagine that such a system could exist, and could improve over time. Every certain time, policymakers could release guidelines as temporary benchmarks to help the compliance process of new uses and developments of (robot) technologies. This system could reduce the current gap between general and theoretical principles typical from policymaking and the technicality and applicability of technical standards; while formalizing a data-generator process for robot developers to inform such policymaking evaluation processes. Indeed, "research and practice need to proceed in parallel so that it actually works" (Adelle et al. 2012).

4.2.2. Proposal 2: integrate stakeholder participation in expost legislative evaluations to increase lawmaking efficacy A recent example of changes in cognitive structures lay on ex-post legislative evaluations. These evaluations are a critical evidence-based judgment of the extent to which an intervention has been active and efficient, relevant given the needs and its objectives, coherent both internally and with other European policy interventions, and it has European added-value (Communication on Smart Regulation 2013; Better Regulation Guidelines 2015). The entire policy appraisal research includes a literature review of the design, performance, and politics of the appraisal, but we focus on the 'learning and evidence utilization' part (Adelle et al. 2012). This part of the literature looks for evidence that the assessment has led to policy change via processes of learning from either an instrumental approach, mainly when the knowledge informs directly concrete decisions; or from a conceptual one, a more soft-power approach, meaning that new information, ideas, and perspectives influence policymakers and, thus, little by little the policy system (Hertin et al. 2009).

The problem with this approach is that it is challenging to study learning processes over long time periods. Instrumental learning may also happen at the conceptual but not at the practical level (Radaelli and Meuwese 2009). In this line, some authors agree on the fact that even though there are institutional constraints that make sure the assessment is carried out, such assessment only follows a political agenda but it does not honestly examine the fundamental premises and underlying problem formulation (Nilsson 2005; European Court of Auditors 2010). If stakeholder were to participate in such evaluation processes, then they should contribute to the addressing of these fundamental and core issues.

In light of a new robot development or use, we suggest that developers should assess how available and new policymaking have affected them, compile barriers and constraints they found on the process, and let the regulator know. The regulator could react upon this information and include such knowledge into their subsequent evaluation process. In the beginning, both the data generation and the data collection are going to be certain time-consuming. Over time, automated processes can undoubtedly help speed the process. 
4.2.3. Proposal 3: make codes of conduct binding by means of including in a regulation, in a private contract or criminal clauses, or publishing shaming lists

In the Resolution 2015/2103(INL), the EP affirms, 'clear, strict and efficient guiding ethical framework for the development, design, production, use, and modification of robots is needed.' In that respect, they propose a framework consisting of a code of conduct for robotics engineers, a code for research ethics committees, and two licenses, one for designers and the other one for users. Some of the principles enshrined in such corpus relate to the Beauchamp and Childress' biomedical ethical framework (beneficence, non-maleficence, autonomy and justice) (Beauchamp and Childress 2001), the respect for fundamental rights, and the consideration of precaution, inclusiveness, accountability, safety, reversibility, privacy or the maximization of benefit and the minimization of harm.

Linked to the pressures aimed at achieving cognitive structure change, one of the problems of soft-law is the lack of the capacity for enforcement. Allegations and defenses are not allowed under accepted standards and procedures in light of a violation. In other words, the soft law does not establish consequences for violations (Abbott and Snidal, 2000). Adherence to a standard is voluntary and only checked by a certification agency. This process has mainly been criticized because the certification agency does not usually and adequately checks the processes or the product itself. Moreover, certification agencies have no type of responsibility.

To 'set of general principles and guidelines for actions to be taken by all stakeholders' as the EP suggests, we propose to make these codes of conduct binding, 'harder' in a legal sense. This process would entail the establishment of consequences for any violation (Abbott and Snidal, 2000). There are different ways to achieve this goal: (1) creating a regulation that can enforce such codes of conduct could achieve that goal; (2) including them in private contracts and criminal law provisions; or (3) publishing shaming lists and advertisements at the addressee's expenses.

(1) As regards the first proposal, making the code binding would entail either civil or criminal sanctions, under the conditions determined by the law. The 'hard law' liability may be conceived as a subsidiary, being activated only in cases when the industry or the regulated actor do not adopt and properly implement its internal code of conduct, modeled on the 'public' code of conduct. A recent example of policymaking going in this direction, taken by the field of corporate social responsibility (CSR), is the recent French law 2017-399, on the due diligence on multinationals to prevent serious human rights abuses in supply chains.

(2) The second proposal, to which we already made a short reference, would involve a more active role of State judicial bodies. These latter would be called to interpret existing or future general clauses of contract and criminal law, to 'harden,' so to say, private/hybrid standards. Thus, the reference to 'good faith,' or 'best practices,' among others, would be filled with principles coming from ethical and non-technological based documents (Beckers 2016). A significant example of this attitude, again taken from the CSR field, is the case Ajax in Brazil, where a criminal judge made a significant reference to WHO standards to assess the criminal responsibility-based on State law provisions-of a corporate actor (Ventura 2016).

More generally, and once again based on a systems theory approach, the usefulness of 'public' standards and codes of conduct should be measured, assessed and potentiated keeping in mind the productive interactions with the internal normativity of private actors, i.e., on the impact on private/hybrid legal orders (Teubner 2011). To this end, legal sanctions constitute only one of the available means.

As we have already seen, in a broader context, social reactions may constitute further and sometimes more effective 'sanctions,' with more dissuasive capacity than hard law (Teubner and Beckers 2013; Catà Backer 2008a, b). However, State law may have a crucial role in 'activating' and potentiating, so to say, such reactions. That is why our final proposal is that State and public regulators establish a duty upon the robot technology industries and producers, to publicly declare their adhesion to any existing and upcoming standard or code of conduct. An alternative would be the publication by State bodies of 'shaming lists' of the robot technology industries which do not adhere to any-either public or privatestandard or code. These duties would not impose any specific, substantial obligation per se, but would activate the reaction of the 'spontaneous sectors' of functional systems: public opinion, consumers or social movements. Once again, a significant example comes from the CSR field. Namely, the disclosed systems and the duty for the biggest corporations to publish reports concerning their extra-financial activities. Also, the way they take into consideration the ethical and social impacts of their conducts, established by the EU Directive 2012/34, which in turn, was modeled on the French law 2010-788 (so-called loi Grenelle II) (Catà Backer 2008a, 2008b; Campbell and Vick 2007; Eickenjäger 2016). Although these models of externally-induced transparency are often not sufficient, due to administrative inefficiency and strategic business avoidance, they have proven to be sufficient to a certain extent, especially when sustained by the constant pressure of civil society, NGOs and strategic litigation (Catà Backer 2008a, 2008b).

\section{Conclusions}

In this paper, we have investigated the challenges of overlapping public/private regulatory initiatives that govern robot technologies in general, and in the concrete of healthcare robot technologies. We wondered until what extent robotics should be governed only by standards, and concluded that hybrid private/public regulatory models could be.

First, we argued that, due to their specific nature of private soft-law, current standards governing robot technology tend to be single-principle-based-in this case, safety. Private standards tend to disregard other legal principles and values deeply embedded in the social environment where they are implemented, i.e., in the social systems where humans and robot technology operate. Coupled with the lack of a broader legal dimension, furthermore, these standards lack social legitimacy and accountability. 
We sustain the idea that public policymaking provides comprehensive protection to robot users throughout the article, something supported by recent European institutions (Resolution 2015/2103(INL) 2017 and EC Response to Resolution 2015/2103(INL)). Still, current hard-law sources and prospective law-making processes are far from being wellsuited for emerging robot technologies. The volatility of the field hinders the understanding of associated risks and impacts, and the anticipation of effective measures to mitigate them. In this respect, several examples helped illuminate existing dissonances between new robot public regulatory initiatives and the feasibility of their implementation.

The 'better regulation' approach of the EU may increase the use of evidence to inform policy and lawmaking, and the involvement of different stakeholders. However, current hardlawmaking instruments do not appear to take advantage of the knowledge produced by standard-based regulations, virtually wasting their potential benefits. This fact affects the legal certainty with regards to a fast-paced changing environment like robotics.

Inspired by the systems theory, the article ends identifying two different moments in time to integrate stakeholder know-how into policymaking. In this respect, we have proposed linking technology impact assessments with regulatory impact assessments via the creation of shared data repositories. Another proposal referred to the strengthening process of private standards via their inclusion in regulation, in private contracts or through social and reputational sanctions.

\section{Supplementary materials}

Supplementary material associated with this article can be found, in the online version, at doi:10.1016/j.clsr.2018.12.009.

\section{REFERENCES}

Abbott KW, Snidal D. Hard and soft law in international governance. Int Organ 2000;54:421-56.

Adelle C, et al. Proceeding in parallel or drifting apart? A systematic review of policy appraisal research and practices. Environ Plan 2012;30(3):401-15.

Ayers I, Braithwaite J. Responsive Regulation: Transcending the Deregulation Debate. Oxford; 1992.

Bacon, Jean and Michels, Johan David and Millard, Christopher and Singh, Jatinder, Blockchain demystified (December 20, 2017). Queen Mary School of Law Legal Studies Research Paper No. 268/2017. Available at SSRN:

https://ssrn.com/abstract=3091218;

Beauchamp TL, Childress JF. Principles of Biomedical Ethics. USA: Oxford University Press; 2001.

Beckers, A., Regulating corporate regulators through contract law? The case of corporate social responsibility codes of conduct (2016). EUI Working Papers - Max Weber Programme 2016/12. Available at SSRN: https://ssrn.com/abstract=2789360

Bergamasco M, Allotta B, Bosio L, Ferretti L, Parrini G, Prisco GM, et al. An arm exoskeleton system for teleoperation and virtual environments applications. 1994 IEEE International Conference on Robotics and Automation Proceedings; 1994. p. $1449-54$.
Breazeal C, Scassellati B. How to build robots that make friends and influence people. 1999 IEEE/RSJ International Conference on Intelligent Robots and Systems; 1999. p. 858-63.

Bryson JJ, Diamantis ME, Grant TD. Of, for, and by the people: The legal lacuna of synthetic persons. Artif Intell Law 2017;25(3):273-91.

Bomhoff J, Meuwese A. The meta-regulation of transnational private regulation. J Law Soc 2011;1:138.

Boucher Philip. Domesticating the drone: The demilitarisation of unmanned aircraft for civil markets. Sci Eng Ethics 2015;21(6):1393-412.

Butler Declan. A world where everyone has a robot: Why 2040 could blow your mind. Nature 2016;530:398-401.

Braithwaite J. Enforced self-regulation: A new strategy for corporate crime control. Michigan Law Rev 1982;80:1466.

Cafaggi F. New foundation of transnational private regulation. J Law Soc 2011;1:20.

Caldwell Darwin G, Kocak O, Andersen U. Multi-armed dexterous manipulator operation using glove/exoskeleton control and sensory feedback. IROS 1995;2:567-72.

Callies G-F, Renner M. Between law and social norms: The evolution of global governance. Ratio Juris 2009;2:260.

Calo Ryan. The drone as a privacy catalyst. Stan. L Rev Online 2011;64:29.

Calo Ryan, Michael Froomkin A, Kerr Ian. eds. Robot law. Edward Elgar Publishing; 2016.

Campbell, Vick. Disclosure law and the market for corporate social responsibility. In: McBarnet D, Voiculescu A, Campbell T, editors. The New Corporate Accountability. Cambridge: Corporate Social Responsibility and the Law; 2007. p. 241-78.

Cassese S. The Global Polity: Global Dimension of Democracy and the Rule of Law. Sevilla; 2012.

Backer Catà. Economic globalization and the rise of efficient systems of global private law Making: Wal-Mart as global legislator. Connecticut Law Rev 2007;4:1739.

Catà backer L. Global panopticism: States, corporations and the governance effects of monitoring regimes. Indiana J Global Legal Stud 2008;15:101.

Catà Backer L. From moral obligation to international law: Disclosure systems, markets and the regulation of multinational corporations. georgetown $\mathrm{j}$ int law 2008;39:59.

Catà Backer L. Private actors and public governance beyond the state: The multinational corporation, the financial stability board, and the global governance order. Ind J Global L Stud. 2011;18:751.

Catà Backer L. Governance polycentrism or regulated self-regulation-Rule systems for human rights impacts of economic activity where national, private and international regimes collide. Coalition for Peace and Ethics Working Paper No. 1/1, 2014.

Cavoukian Ann. Privacy and drones: Unmanned aerial Vehicles. Ontario, Canada: Information and Privacy Commissioner of Ontario, Canada; 2012.

Clarke Roger, Moses Lyria Bennett. The regulation of civilian drones' impacts on public safety. Comput Law Security Rev 2014;30(3):263-85.

Coles J, Faily S, Ki-Aries D. Tool-supporting Data Protection Impact Assessments with CAIRIS. 2018 IEEE 5th International Workshop on Evolving Security \& Privacy Requirements Engineering (ESPRE). IEEE; 2018. p. 21-7.

Collingridge David. The Social Control of Technology. Continuum International Publishing Group Ltd.; 1982.

Danks David, London Alex John. Regulating autonomous systems: Beyond standards. IEEE Intell Syst 2017;32(1):88-91.

Darling K. Extending legal protection to social robots: The effects of anthropomorphism, empathy, and violent behavior towards robotic objects. In: Calo R, Froomkin AM, Kerr I, editors. Robot law. Edward Elgar Publishing; 2016. 
De Hert, P. (2005). Biometrics: legal issues and implications. Background Paper for the Institute of Prospective Technological Studies, DG JRC-Sevilla, European Commission.

De Londras. Privatized sovereign performance: Regulating the 'gap' between security and rights? J Law Soc 2011;1:96.

Delmas-Marty M. Le Flou Du Droit. Paris: Canopé; 1986.

Delmas-Marty M. Le mou, le doux et le flou sont-ils des garde-fous?. In: Clam J, Martin G, editors. Les Transformations De La Régulation Juridique. Paris: LGDJ; 1998. p. 209-19.

Delmas-Marty M. Les Forces Imaginantes Du Droit (II). Le pluralisme Ordonné. Paris: Seuil; 2006.

Delmas-Marty M. Les Forces Imaginantes Du Droit (III). La refondation Des Pouvoirs. Paris: Seuil; 2007.

Eickenjäger. Non-Financial Reporting for Business Enterprises An Effective Tool to Address Human Rights Violations?. In: Blome Franzki, Fischer-Lescano Markard, Oeter, editors. Contested Collisions: Interdisciplinary Inquiries Into Norm Fragmentation in World Society. Cambridge; 2016. p. 226.

European Court of Auditors (2010). Impact Assessments in the EU institutions: Do They Support decision-making?" Special Report Number 3. Luxembourg: European Court of Auditors; 2010.

Febbrajo A, Harste G, editors. Law and Intersystemic Communication: Understanding 'Structural Coupling'. Farnham/Burlington: Ashgate; 2013.

Fenwick, M., Transnational regulatory networks, in Jurčis et al. 2013, pp. 171-186.

Fischer-Lescano A, Teubner G. Regime-collisions: The vain search for legal unity in the fragmentation of global law. Michigan J Int Law 2004;25:999.

Fosch-Villaronga E. Creation of a care robot impact assessment. WASET. Int J Soc Behav Educ Econ Business Ind Eng WASET 2015;9(6):1867-71.

Fosch-Villaronga E. ISO 13482: 2014 and Its Confusing Categories. Building a Bridge Between Law and Robotics. New Trends in Medical and Service Robots. Cham: Springer; 2016. p. 31-44.

Fosch-Villaronga E, Albo-Canals J. Boundaries in play-based cloud-companion-mediated robotic therapies: from deception to privacy concerns. In: Heerink M, Jong Mde, editors. Conference Proceedings, NewFriends 2015, The 1st International Conference on Social Robots in Therapy and Education; 2015. p. 40-1 2015.

Fosch-Villaronga E, Heldeweg MA. Regulation, I presume?", said the robot. towards an iterative regulatory process for robot governance. Comput Law Security Rev. 2018;34(6):1258-77.

Fosch-Villaronga E, Roig A. European Regulatory Framework for Person Carrier Robots. Comput Law Security Rev 2017;33(Issue 4(August)):502-20.

Fosch-Villaronga E, Virk GS. Legal issues for mobile servant robots. In: Rodić A, Borangiu T, editors. Proceedings of the 25th Conference on Robotics Alpe-Adria-Danube Region. Advances in Robot Design and Intelligent Control, 2016.

Fosch-Villaronga E. The importance of integrating technical knowledge in the development of robotic policies: the case of personal care robots. In: Casanovas P, Moreso JJ, editors. Anchoring Institutions. Springer Verlag; 2019 forthcoming.

Glaser A. Ohio is now the fifth U.S. state to permit delivery robots on sidewalks. Recode 2017 https://www.recode.net/2017/7/5/ 15916688/ohio-fifth-state-delivery-food-robots-starship-law, last modified July 5, 2017.

George Carlisle, Whitehouse Diane, Duquenoy Penny. eds. eHealth: legal, Ethical and Governance Challenges. Springer Science \& Business Media; 2012.

Guihot Michael, Matthew Anne F, Suzor Nicolas. Nudging Robots: Innovative Solutions to Regulate Artificial Intelligence. SSRN; 2017
Gunningham N, Kagan RA, Thornton D. Social license and environmental protection: Why businesses go beyond compliance. Law Soc Inquiry 2004;29:307.

Hennebel L, Lewkowicz G. Corégulation et responsabilité sociale des entreprises, in corporate social responsibilty. In: Berns T, Docquir P-F, Frydman B, Hennebel L, Lewkowicz G, editors. Responsabilité Des Entreprises Et Corégulation. Bruxelles: Bruylant; 2007. p. 147-226.

Hertin J, et al. Rationalising the policy mess? Ex ante policy assessment and the utilisation of knowledge in the policy process. Environ Plan A 2009;41(5):1185-200.

Holder C, Khurana V, Harrison F, Jacobs L. Robotics and law: Key legal and regulatory implications of the robotics age (Part I of II). Comput Law Security Review 2016;32(3):383-402.

Hutter Bridget M. A risk regulation perspective on regulatory excellence. In: Coglianese Cary, editor. Achieving Regulatory Excellence. Washington, USA: Brookings Institution Press; 2016. p. 101-14.

Howard-Grenville Nash, Coglianese. Constructing the license to operate: Internal factors and their influence on corporate environmental decisions. Law Policy 2008;30:73.

ISO/IEC, Guide 2, Standardization and related activities - General vocabulary, 2004. https://www.iso.org/standard/39976.html

ISO/IEC 29134: 2017 Information technology - Security techniques -Guidelines for privacy impact assessment. https://www.iso.org/standard/62289.html

Johnson Deborah G. Technology with no human responsibility? J Busi Ethics 2015;127(4):707-15.

Jurčis PF, Kjaer P, Yatsunami R, editors. Regulatory Hybridization in the Transnational Sphere. Leiden-Boston: Martinus Nijhoff; 2013.

Kjaer P. Transnational normative orders: The constitutionalism of intra- and trans-normative law. Ind J Global Legal Stud. 2013;20:777.

Kjaer P. The metamorphosis of the functional synthesis: A continental european perspective on governance, law, and the political in the transnational space. Wis L Rev. 2010;2010:489.

Koops BJ, Leenes R. Privacy regulation cannot be hardcoded. A critical comment on the 'privacy by design'provision in data-protection law. Int Rev Law Comput Technol 2014;28(2):159-71.

Konok V, Korcsok B, Miklośi A', Gaćsi M. Should we love robots?-The most liked qualities of companion dogs and how they can be implemented in social robots. Comput Hum Behav 2018;80:132-42.

Ladeur, K.-H., The Theory of autopoiesis as an approach to a better understanding of postmodern law. From the hierarchy of norms to the heterarchy of changing patterns of legal inter-relationships, EUI Working Paper LAW No. 99/3 (Badia Fiesolana: EUI, 1999).

Laukyte Migle. The Capabilities Approach As a Bridge Between Animals and Robots. European Institute Working Papers; 2013.

Lessig L. Code: And Other Laws of Cyberspace, Version 2.0. Basic Books; 2006.

Luhmann N. Die Weltgesellschaft. Archiv für Rechts und Sozialphilosophie 1971;57:21.

Marchant Gary E, Allenby Braden R, Herkert Joseph R. The Growing Gap Between Emerging Technologies and Legal-Ethical oversight: The pacing Problem, 7. Springer Science \& Business Media; 2011.

Michaels R. The re-statement of non-state law. The state, choice of law, and the challenge from global legal pluralism. Wayne Law Rev 2005;51:1209.

Miller David P, Slack Marc G. Design and testing of a low-cost robotic wheelchair prototype. Auton Robots 1995;2(1): $77-88$ 
Nilsson M. The role of assessments and institutions for policy learning: A study on Swedish climate and nuclear policy formation. Policy Sci 2005;38(4):225-49.

Notario N, Crespo A, Martín García YS, Álamo Ramiro JM, Le Métayer D, Antignac T, et al. PRIPARE: Integrating privacy best practices into a privacy engineering methodology. "IEEE Security and Privacy Workshops (SPW 2015)", 21/05/2015 22/05/2015. San Jose, California: EE.UU; 2015. p. 151-8.

Pillath Susanne. Briefing On Automated Vehicles in the EU. European Parliamentary Research Service (ERPS); 2016.

Radaelli CM, Meuwese A. Better regulation in Europe: Between public management and regulatory reform. Public Admin 2009;87(3):639-54.

Renner. Occupy the system! Societal constitutionalism and transnational corporate accounting. Indiana Journal of Global Legal Studies 2013;20:941.

Rodić Aleksandar, et al. "Development of Human-Centered Social Robot with Embedded Personality For Elderly Care." New Trends in Medical and Service Robots. Cham: Springer; 2016. p. 233-47.

Sabel C, Herrigel G, Kristensen PH. Regulation under uncertainty: The coevolution of industry and regulation. Regul Gov. 2018;12(3):371-94.

Salem M, et al. Towards safe and trustworthy social robots: Ethical challenges and practical issues. In: Tapus A, et al, editors. Social Robots. Springer International Publishing; 2015. p. 584-93.

Senden L. Soft law, self-regulation and co-regulation in European law: where do they meet?; 2005.

Shelton D. Commitment and Compliance: The role of Non-Binding Norms in the International Legal System. Oxford University Press; 2003.

Simmonds P, Brown N, Rentel M. Evaluation of directive 2006/42/EC On Machinery. Final Report. Technopolis Group; 2017.

Snyder. Private lawmaking. Ohio State Law J. 2003;64:371.

Spiliopoulou-Kaparia, M. (2017) The evaluation of Directive 85/374/EEC on liability for defective products and Directive 2006/42/EC on machinery. European Stakeholder Forum Workshop on Regulatory challenges for a digitizing industry Essen, 1st of February 2017

Stanton KB, Sherman PR, Rohwedder ML, Fleskes CP, Gray DR, Minh DT, et al. PSUBOT-a voice-controlled wheelchair for the handicapped. IEEE Proceedings of the 33rd Midwest Symposium on Circuits and Systems; 1990. p. 669-72.

Strange S. States and Markets. London-New〉sYork: Printer; 1988.

Teubner G. After privatization? The many autonomies of private law. Curr Legal Problems 1998;51:393.

Teubner G. Altera Pars Audiatur: Law in the collision of discourses. In: Rawlings R, editor. Law, Society and Economy. Oxford: Clarendon; 1997. p. 149-76.
Teubner G. Breaking frames: Economic globalisation and the emergence of Lex Mercatoria. Eur J Soc Theory 2002;5:199.

Teubner G. Rights of non-humans? Electronic agents and animals as new actors in politics and law. J Law Soc. 2006;33(4):497-521.

Teubner G. Constitutional Fragments: Societal Constitutionalism and Globalization. Oxford: OUP; 2012.

Teubner G. Juridification concepts, aspects, limits, solutions. In: Teubner G, editor. Juridification of Social Spheres: A Comparative Analysis in the Areas of Labor, Corporate, Antitrust and Social Welfare Law. Berlin-New/sYork: De Gruyter; 1987. p. 3-48.

Teubner G. Law As an Autopoietic System. Oxford-Cambridge: Blackwell; 1993.

Teubner G. Self-constitutionalizing TNCs? On the linkage of "private" and "public" corporate codes of conduct. Indiana J Global Legal Stud 2011;18:17.

Teubner G. Substantive and reflexive elements in modern law. Law Soc Rev 1983;17:239.

Teubner G. Societal constitutionalism: Alternatives to state-centered constitutional theory?. In: Joerges C, Sand I-J, Teubner G, editors. Constitutionalism and Transnational Governance. Oxford: OUP; 2004. p. 3-28.

Teubner G, Beckers A. Expanding constitutionalism. Ind J Global Legal Stud 2013;20:523.

Teubner G, Korth P. Two kinds of legal pluralism: Collision of laws in the double fragmentation of world society. In: Young M, editor. Regime Interaction in International Law: Theoretical and Practical Challenges. Cambridge: CUP; 2012. p. 23-54.

Tully S. Corporations and International Lawmaking. Leiden: Martinus Nijhoff; 2007.

Vayena E, Gasser U. Between openness and privacy in genomics. PLoS Med 2016;13(1).

Ventura D. L'arret Ajax et l'application du droit de l'Organisation Mondiale de la Santé au Brésil: un cas de "durcissement » de la soft law par le juge national. In: Martin-Chenut K, de Quenaudon R, editors. Développement rurable: Mutations Ou Métamorphoses De La Responsabilité. Paris: Pedone; 2016. p. 289-305.

Vesting. The autonomy of law and the formation of network standards. German Law J 2004;5:639.

Wright D, De Hert P. Introduction to privacy impact assessment. Privacy Impact Assessment. Dordrecht: Springer; 2012. p. 3-32.

Wright D. Making privacy impact assessment more effective. Inform Soc 2013;29(5):307-15.

Wright D, Finn R, Rodrigues R. A comparative analysis of privacy impact assessment in six countries. J Contemp Eur Res 2013;9(1).

Zumbansen P. Neither 'public' nor 'private', 'national' nor 'international': Transnational corporate governance from a legal pluralist perspective. J Law Soc 2011;1:50. 